\title{
Induction of reparative dentin by calcium silicate-based material as direct pulp capping agent
}

\author{
Mozammal Hossain, Mahmood Sajedeen and Yukio Nakamura
}

\section{Article Info \\ Department of Conservative Dentistry and Endodontics, Faculty of Dentistry, Bangabandhu Sheikh Mujib Medical University, Shahbag, Dhaka, Bangladesh (MH, MS); Institute of Clinical Dentistry and Department of Biomaterials, The Faculty of Dentistry, University of Oslo, Blindern N-0317, Norway (YN) \\ For Correspondence: \\ Mozammal Hossain \\ mozammalresearch@gmail.com \\ Received: \\ Accepted: \\ 12 November 2019 \\ Available Online: 23 December 2019}

ISSN: 2224-7750 (Online)

2074-2908 (Print)

DOI: $10.3329 /$ bsmmuj.v12i4.43857

Keywords: Calcium silicate; Pulp capping; Reparative dentin

\section{Cite this article:}

Hossain $M$, Sajedeen $M$, Nakamura $Y$. Induction of reparative dentin by calcium silicate-based material as direct pulp capping agent. Bangabandhu Sheikh Mujib Med Univ J. 2019; 12: 182-86.

\section{Copyright:}

The copyright of this article is retained by the author(s) [Atribution CC-By 4.0]

\section{Available at:}

www.banglajol.info

A Journal of Bangabandhu Sheikh Mujib Medical University, Dhaka, Bangladesh

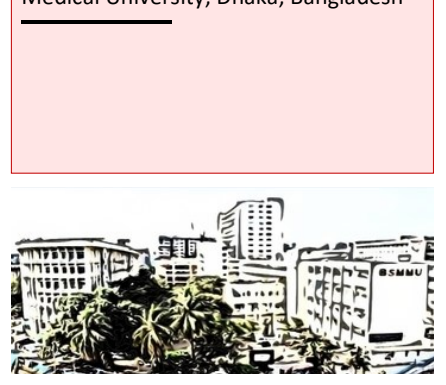

\section{Abstract}

This study was performed to examine whether calcium silicate could induce reparative dentin formation without eliciting any adverse effect in direct pulp capping of premolar teeth. Twenty participants who need extraction of their 4 healthy permanent premolar teeth for orthodontic reasons were included in this study. Following the surgical procedure, the exposed pulp tissue was treated either with calcium silicate or covered with calcium hydroxide paste. On day 3, 7, 14 and 28, the experimental teeth was extracted and examined using light microscopy and histometric analysis to observe the inflammatory changes and the amount of reparative dentin formation. The results showed that in the calcium silicate treated teeth, substantial amounts of dentine-like tissue was formed on day 14 and mostly located on the exposure site. It was also observed in the calcium hydroxide treated teeth but dentin-like tissue located at a distance from the exposure site. The total amount of reparative dentine formed in the calcium silicate-treated teeth was significantly higher $(\mathrm{p}<0.005)$ than in the calcium hydroxide-treated specimens. In conclusion that the calcium silicate indices pulpal wound healing and reparative formation in the exposed teeth without affecting the normal function of the remaining pulp.

\section{Introduction}

The treatment of deep carious lesion is still a controversial issue in the operative dentistry because of the traditional concept of complete carious tissue removal in a deep preparation has been challenged. Furthermore, complete carious dentin removal is not always essential to arrest the carious progression because the bacteria in the dentin may cause pulpal inflammation but there is a chance of pulp regeneration too. 1 Therefore, preservation of the pulp vitality in the treatment of deep carious lesion is considered as beneficial as that of endodontic treatment. However, if the pulp has become exposed during caries removal, the successful outcome could be significantly reduced. In that case, pulp healing with indirect and direct pulp capping procedures have been suggested by some of the previous studies. $.2-7$

Direct pulp capping is a procedure, where an exposed pulp is covered by a dressing in an attempt to preserve the pulp vitality. The objective is to stimulate the pulp tissue to close the exposure by hard tissue formation without inflammatory changes in the residual pulp. However, the success of treatment depends on the materials used which are known as pulp capping material.
The dentinal pulp has an inherent capability to produce reparative dentin when the local environment is favorable, $\underline{3}$ and it can be expected that bio-induction of dentin formation will change the outcome of pulp therapy dramatically, clarifying the factors and mechanism associated with such healing is a critical issue not only for scientific reason, but also for clinical practice. However, no biological strategy for the controlled induction of reparative process, e.g. application of conventional calcium hydroxide, has so far been successful for clinical use in the dental pulp..$\underline{4-7}$

Calcium hydroxide paste commonly applied to the cap accidental pulp exposure and pulpal wall in the cavities to protect the pulp and induces new hard tissue formation. In endodontics, freshly prepared calcium hydroxide pastes are often preferred as pulp-capping agents in direct pulp capping and pulpotomy due to their favorable $\mathrm{pH}$ and subsequent antimicrobial and anti-inflammatory effect.

Recently, calcium silicate-based material is used as a dentin restorative material, also has indication in endodontic. $.4-7$ The main component of the powder is a tri-calcium silicate, with the addition to the powder of calcium carbonate and zirconium dioxide. The liquid is a solution of calcium chloride with a water 
reducing agent. Advantages of this material include chemico-mechanical bonding with tooth and composite, high compressive and flexure strength. However, a few studies have been performed on the effect of calcium silicate in healthy pulp tissue. $.8-12$ Therefore, the clinical and histological outcome of calcium silicate in healthy teeth is needed to be justified.

The present study was performed to examine whether calcium silicate could induce reparative dentin formation without eliciting any adverse effect in direct pulp capping of premolar teeth, in vivo. Furthermore, to avoid adverse effect from high $\mathrm{pH}$ preparation of calcium hydroxide preparation, the tissue friendly low $\mathrm{pH}$ calcium hydroxide paste was used as a positive control.

\section{Materials and Methods}

This prospective clinical trial was performed at the Department of Conservative Dentistry and Endodontics from January to December 2018.

\section{Surgical procedure}

Non-carious permanent premolar teeth from 20 participants (4 teeth of each participant), who need extraction of their teeth for orthodontic reasons, were used as study population. These teeth were divided by traditional lottery method of which 2 teeth used for calcium silicate-based material and two for calcium hydroxide paste in each participant. Therefore, as a total, among the 20 patients, 40 teeth were used for calcium silicate and 40 teeth for calcium hydroxide. These teeth were divided into four groups (10 teeth in each group) according to observation times as follows: day 3, 7, 14 and 28.

\section{Exposure of the pulp}

After application of local anesthesia and mouth preparation, a round shape cavity (diameter: $2 \mathrm{~mm}$ ) was prepared on the occlusal surface to expose the pulp using a flat end fissure bur (Shofu Dental Corporation, Japan) with a high speed hand piece under sufficient cooling arrangement.

\section{Treatment}

In calcium silicate group, following control of bleeding with sterile cotton pellets, the exposed pulp tissue was covered with calcium silicate-based material (Biodentine ${ }^{\mathrm{TM}}$, France) according to the manufacturer's recommendation. The liquid from single ampoule was emptied in the capsule and the capsule was triturated for $30 \mathrm{sec}$ on a mixing device (Cap-mix) at a speed of 4,000-4,200 rotation/min. The freshly mixed material has a putty-like consistency and was packed in the exposure site using a plastic filling instrument (supplied by the manufacturer). The working time was up to $6 \mathrm{~min}$ with a final set at around 10-12 min. Finally restoration of the tooth was performed with flowable composite resin.

In calcium hydroxide paste group, following control of bleeding with sterile cotton pellets, the exposed pulp tissue was covered with Dycal ${ }^{\circledR}$ (DENTSPLY, Germany) according to manufacturer's recommendation. All procedures were performed by the same operator.

\section{Qualitative analysis: Sampling and histology}

On day $3,7,14$ and 28 after pulp capping, teeth were extracted under local anesthesia and fixed in cold $4 \%$ neutral buffered formaldehyde for 24 hours. The specimens were demineralized and embedded in paraffin. After longitudinal serial sectioning $(6 \mu \mathrm{m})$, serial sections of each sample were stained with hematoxylin and eosin. Each sample containing pulp tissue was then observed by a blinded observer in a light microscope equipped with a digital camera and computer for histometry.

\section{Quantitative analysis of new hard tissues}

The amount of new hard tissue formed subjacent to each treatment was assessed from best histological sections of the each experimental tooth prepared for qualitative analysis. The area covered by newly formed hard tissue in these sections was measured by digital histometry equipment.

\section{Statistical analysis}

Results were given as the mean for each tooth and data were collected and then analyzed by computer -based statistical software Statistical Package of Social Science (SPSS) version 20 (SPSS Inc., USA). Student's t-test was performed to assess the differences between two groups and a value of $\mathrm{p}<0.05$ was considering as statistically significance.

\section{Results}

The histological appearance of calcium silicatetreated teeth on day 3, 7, 14 and 28 were as follows: on day 3, except in 2 cases, neither inflammation nor any necrotic zone was recognized (Figure 1A). On day 7, an increased in cellular and fibroblastic basophilic layer was observed. Vascular degeneration was also observed in the odontblastic layer of the surgical site. In the cells that had undergone degeneration, large and small vacuole degeneration was observed (Figure 1B). On day 14 and 28, partly calcified fibrous tissue lined by odontoblastic cells was seen below the calcium silicate-based material. Furthermore, neither necrosis nor any inflammation was recognized in any case on day 14 and 28 . The zone of new dentin like structure (reparative dentin) was identified but they incompletely covered the pulp (Figure 1C,D). Two calcium silicate-treated teeth were necrosed on day 3 but were healed on day 14 and 28 by the following way; 
Table I

\begin{tabular}{|c|c|c|c|c|c|c|c|c|}
\hline \multicolumn{9}{|c|}{ Results of induction between two groups } \\
\hline & \multicolumn{4}{|c|}{ Calcium silicate-based material } & \multicolumn{4}{|c|}{ Calcium hydroxide paste } \\
\hline & Day 3 & Day 7 & Day 14 & Day 28 & Day 3 & Day 7 & Day 14 & Day 28 \\
\hline \multicolumn{9}{|l|}{ Inflammation status } \\
\hline Slight or no inflammation & 8 & 8 & 10 & 10 & 2 & 2 & 10 & 10 \\
\hline Necrosis & 2 & 2 & 0 & 0 & 8 & 8 & 0 & 0 \\
\hline \multicolumn{9}{|l|}{ Dentin bridge formation } \\
\hline Partially complete & 0 & 4 & 8 & 8 & 0 & 2 & 0 & 2 \\
\hline Complete & 0 & 0 & 0 & 0 & 0 & 0 & 0 & 0 \\
\hline Incomplete & 10 & 6 & 2 & 2 & 10 & 8 & 8 & 8 \\
\hline \multicolumn{9}{|l|}{ Dentin bridge location } \\
\hline Exposure site & - & 4 & 8 & 8 & - & 2 & 2 & 2 \\
\hline Other locations & - & 6 & 2 & 2 & - & 8 & 8 & 8 \\
\hline Dentin bridge thickness $(\mu \mathrm{m})$ & - & - & $1.0 \pm 0.3$ & $1.4 \pm 0.2$ & - & - & $0.7 \pm 0.1$ & $0.7 \pm 0.3$ \\
\hline
\end{tabular}

on day 14, in the surgical site of the dental pulp, odontoblasts had been strongly affected and degenerated, some might have been lost, and as a result, reticular atrophy might have occurred. On day 28, the formation of wide pre-dentin dyed thinly in hematoxilin and eosin was observed along the primary dentin. There was no atopic calcification.

On the other hand, on day 3 necrotic zone adjacent to the calcium hydroxide paste was separated from the healthy pulp tissue by a deep staining basophilic layer (Figure 1E). After 7 days, an increased in cellular and fibroblastic activity was seen (Figure 1F). After 14 days, partly calcified fibrous tissue lined by odontoblastic cells was seen below the calcium protective zone and disappearance of necrotic zone (Figure 1G). After 28 days, zone of new dentin like structure was identified. Furthermore, the newly formed reparative dentin incompletely covered the pulp (Figure $1 \mathrm{H}$ ).

The thickness of reparative dentin formation by calcium silicate-based material on day 14 and 28 were $1.0 \pm 0.3 \mu \mathrm{m}$ and $1.4 \pm 0.2 \mu \mathrm{m}$, respectively (Table I). On the other hand, thickness of reparative dentin formation by calcium hydroxide paste on day 14 and 28 were $0.7 \pm 0.1 \mu \mathrm{m}$ and $0.7 \pm 0.3 \mu \mathrm{m}$, respectively. The differences between two groups were statistically significant $(p=0.012$ and 0.001 , respectively).

\section{Discussion}

Many studies have been performed to treat exposed pulp by calcium silicate-based material and calcium hydroxide paste and assessed the dentin bridge formation in each material. Tran et. (2012). .13 stated that the structure induced by calcium hydroxide contains several cells called inclusion, formally known as tunnel defects also reported by Nakamura et.al. (2002) $\underline{14}$ and Cox et. al. (1996). $\underline{15}$ These defective areas, as undesirable area, facilitate the migration of microorganism to the pulp and lead to endodontic infections. On the contrary, the formation of a dentin bridge formed by calcium-silicate based material showed a well-localized pattern in the affected area, unlike calcium hydroxide. The dentin quality and odontoblast organization was also better in calcium silicate and dentinal tubules were clearly visualized. Furthermore, Jalan et. al. (2017) 16 in a clinical study on 45 human premolar teeth, showed that after 45 days of direct pulp capping with calcium silicate and calcium hydroxide, dentin bridge in the teeth coated with calcium silicate were consistently thicker and more continuous and had less dentinal inflammation was seen in comparison with calcium hydroxide.

The pulpal response to capping with calcium hydroxide has been investigated by many previous studies which have similar and dissimilar with the present study. Schroder (1985)17 indicated that when pulp capping is successful, a calcified barrier commonly termed a hard tissue or dentine bridge forms across the exposure. The present study indicated that when calcium silicate is applied, this bridge generally forms directly against the capping material but with calcium hydroxide paste, the reparative dentin formed at a distance from the capping material and a necrotic zone was found between them. However, in some cases, both calcium silicate and calcium hydroxide develops bridge at a distance at a distance from the capping material. The reason for this inconsistent reaction is 

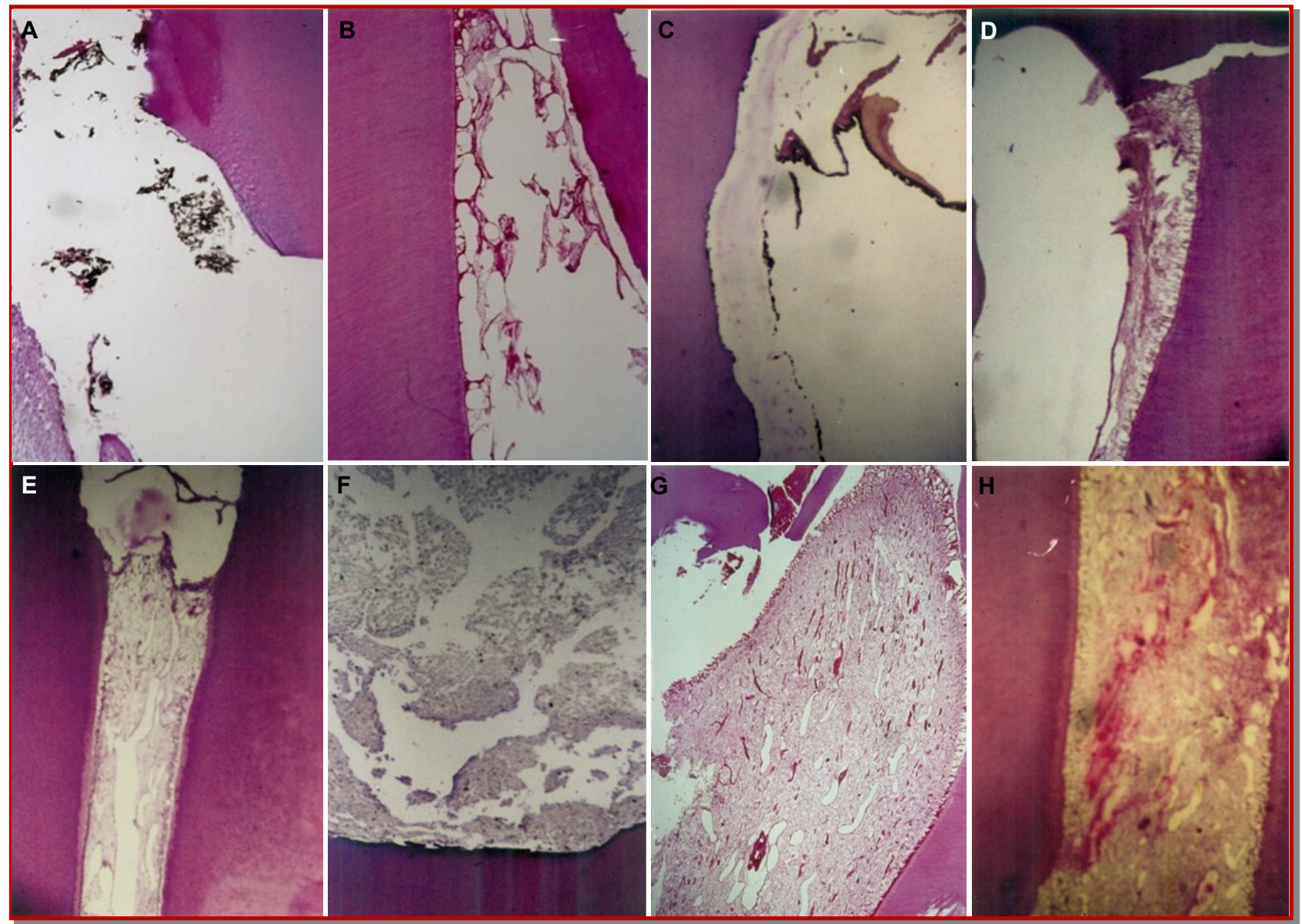

Figure 1: Histological appearance of longitudinal sections of treated teeth with calcium silicate (upper raw) and calcium hydroxide paste (lower raw). Sectioned stained with hematoxylin and eosin, original magnification $40 \times$. Amputated pulp treated with calcium silicate on day 3 (A), day 7 (B), day 14 (C) and day 28 (D), Amputated pulp treated with calcium hydroxide on day 3 (E), day 7 (F), day 14 day (G) and day 28 day $(\mathrm{H})$

not clear, but it was confirmed by Costa et. al. (2003) $\underline{18}$ observation that when there is little pulpal inflammation, the bridge forms against the capping material, but when inflammation is more severe, the bridge forms at a distance.

It is, therefore, still a controversial event that formation of dentin at the exposure site is necessary for pulp healing or not. The condition is more crucial when they are associated with chronic inflammation, abscess and pulpal necrosis. Histological examinations of the dentin bridge by light and scanning electron microscopes show that the bridge may be perforated by vascular channels, though this has been frequently reported. Holland et. al. (1999) 19 however, have demonstrated in monkeys that the dentin bridge is not as permeable as originally thought and can provide a satisfactory barrier to bacterial contamination. If the cavity is not adequately sealed, then bacterial microleakage can occur, and bacteria or their toxins can cross the incomplete bridge to cause or aggravated existing pulpal inflammation, leading to abscess and even- tual necrosis. Therefore, depending on the severity or timing of the microleakage, the healing of the dental pulp may be halted at different stages of the repair process, giving the histological picture of failure of the capping procedure despite dentin bridge formation. Thus, dentin bridge formation depends on the marginal seal of the restoration. This might be another reason of pulpal inflammation or necrosis found in the present study in calcium hydroxide and calcium silicate-based material.

The mechanism of dentin bridge formation is not clarified in the present study. Shayengan et. al. (2012) 20 conducted a study on the response of pigs to calcium silicate pulpotomy in 7, 28 and 90 days follow-up. Their results indicate that calciumsilicate based material has bioactive characteristics; it repairs hard tissues and does not induce any moderate to severe pulp inflammation. They also pointed out that this material had the ability to maintain a marginal integrity due to the formation of hydroxyapatite crystals that could increase 
sealing ability. Due to its excellent sealing ability, there is no risk of microleakage that causes the pulp to be infected or necrosis and does not endanger the success of vital pulp therapy.

\section{Conclusion}

Calcium silicate-based material is capable to induce pulpal wound healing and reparative formation in the exposed teeth without affecting the normal function of the remaining pulp.

\section{Ethical Issue}

The research protocol was approved by the committee and permission for the study was taken from the Institutional Review Board of Bangabandhu Sheikh Mujib Medical University (BSMMU/2018/174).

\section{Conflict of Interest}

Authors declare no conflict of interest.

\section{Acknowledgement}

This work was supported by the research grant for teacher, Bangabandhu Sheikh Mujib Medical University.

\section{References}

1. Gruythuysen RJ, van Strijp AJ, Wu MK. Long-term survival of pulp treatment primary and permanent teeth with clinically diagnosed deep carious lesions. J Endod. 2010; 36: 1490-93.

2. Miyashita H, Worthington HV, Qualtrough A, Plasschaert A. Pulp management for caries in adults: Maintaining pulp vitality. Cochrane Database Syst Rev. 2012.

3. Yamamura T. Differentiation of pulpal cells and induction influences of various matrices with reference to pulpal wound healing. J Dent Res. 1985; 64: 530-40.

4. Ranly DM, Garcia-Godoy F. Current and potential pulp therapies for primary and young permanent teeth. J Dent. 2000; 28: 153-61.

5. Rajasekharan S, Martens LC, Cauwels RGEC, Verbeeck RMH. Biodentine ${ }^{\mathrm{TM}}$ material characteris-tics and clinical applications: A review of the literature. Eur Arch Paediatr Dent. 2014: 15: 147-58.

6. Strassler HE, Levin R. Biodentine, active biosilicate technology for direct and indirect pulp capping. Oral Health. 2012; 102: 52.

7. Katge FA, Shivasharan PR, Patil D. Sealing ability of mineral trioxide aggregate Plus ${ }^{\mathrm{TM}}$ and Biodentine $^{\mathrm{TM}}$ for repair of furcal perforation in primary molars: An in vitro study. Contemp Clin Dent. 2016; 7: 487-92.

8. Katge FA, Patil DP. Comparative analysis of 2 calcium silicate-based cements (biodentine and mineral trioxide aggregate) as direct pulp-capping agent in young permanent molars: A split mouth study. J Endod. 2017; 43: 507-13.

9. Jitaru S, Hodisan I, Timis L, Lucian A, Bud M. The use of bioceramics in endodontics: Literature review. Clujul Med. 2016; 89: 470-73.

10. Poggio C, Beltrami R, Colombo M, Ceci M, Dagna A, Chiesa M. In vitro antibacterial activity of different pulp capping materials. J Clin Exp Dent. 2015; 7: e584-88.

11. Nowicka A, Wilk G, Lipski M, Kolecki J, Buczkowska-Radlinska J. Tomographic evaluation of reparative dentin formation after direct pulp capping with $\mathrm{Ca}(\mathrm{OH})_{2}$, MTA, biodentine, and dentin bonding system in human teeth. J Endod. 2015; 41: 1234-40.

12. Tziafa C, Koliniotou-Koumpia E, Papadimitriou S, Tziafas D. Dentinogenic responses after direct pulp capping of miniature swine teeth with Biodentine. J Endod. 2014; 40: 1967-71.

13. Tran XV, Gorin C, Willig C, Baroukh B, Pellat B, Decup F. Effect of a calcium-silicate-based restorative cement on pulp repair. J Dent Res. 2012; 91: 1166-71.

14. Nakamura Y, Hammarström L, Matsumoto K, Lyngstadaas SP. The induction of reparative dentine by enamel proteins. Int Endod J. 2002; 35: 407-17.

15. Cox CF, Sübay RK, Ostro E, Suzuki S, Suzuki SH. Tunnel defects in dentin bridges: Their formation following direct pulp capping. Oper Dent. 1996; 21: 4-11.

16. Jalan AL, Warhadpande MM, Dakshindas DM. A comparison of human dental pulp response pulpcapping agents. J Conserv Dent. 2017; 20: 129-33.

17. Schroder U. Effects of calcium hydroxide-containing pulp-capping agents on pulp cell migration, proliferation, and differentiation. J Dent Res. 1985; 64: $541-48$

18. Costa CA, Oliveira MF, Giro EM, Hebling J. Biocompatibility of resin-based materials used as pulp-capping agents. Int Endod J. 2003; 36: 831-39.

19. Holland R, de Souza V, Nery MJ, Otobori Filho JA, Bernabe PFE, Dezan Jr E. Reaction of rat connective tissue to implanted dentin tubes filled with mineral trioxide aggregate or calcium hydroxide. J Endod. 1999; 25: 161-66.

20. Shayegan A, Jurysta C, Atash R, Petein M, Abbeele AV. Biodentine used as a pulp-capping agent in primary pig teeth. Pediatr Dent. 2012; 34: e202-08. 